\title{
Research on penetration level of distributed generation in distribution network
}

\author{
Jian $\mathrm{Su}^{1}$, Haitao $\mathrm{Liu}^{1}$, Hao $\mathrm{Bai}^{2}$ Shihong Miao ${ }^{2}$, Pipei Zhang ${ }^{2}$ \\ ${ }^{1}$ China Electric Power Research Institute, Beijing, 100192, China \\ ${ }^{2}$ State Key Laboratory of Advanced Electromagnetic Engineering and Technology, Huazhong \\ University of Science \& Technology, Wuhan, 430074, China
}

Keywords: distributed generation, penetration level, distribution network, static security

\begin{abstract}
To ensure safety and stability of distribution network, the maximum allowable capacity of DG has a certain limit. The maximum allowable capacity can be defined penetration level. The paper first analyses the influence caused by DG on power flow, network loss, node voltage, power quality, current protection and anti-islanding, then introduces some typical evaluation methods for penetration level of distributed generation in distribution network, these methods and conclusions can provide some references for DG planning.
\end{abstract}

\section{Introduction}

With the advantage of relieving the energy crisis and improving power supply reliability, the distributed generation (DG) changes the radial structure of distribution network and affects voltage distribution and line flow. The power flow in the distribution network is no longer a single direction, the bilateral power flow changes voltage attenuation along the feeders. Some nodes can get voltage support from DG, the larger capacity of DG will lead to overvoltage. When distribution network suffers fault, the short-circuit current produced by DG has an influence on original three-phase protection scheme. The existing protection device should be checked whether it can identify and response extra short circuit current. The capacity of DG affects the short-circuit current, so the maximum capacity of DG should be determined to make protection device in normal running. Based on power electronic equipment including rectifier and inverter. DG flexibly control the output power and access to distribution network, but these equipment produce harmonic pollution and reduce the power quality.

DG will bring profound influence on the entire grid, its influence is mainly manifested in the following several aspects: (1) Power flow and the network loss. At least one node in the system of DG output is greater than the load of the node, and the whole system of DG output is greater than the total load in the system. If the total output of DG is more than twice the total load, the network loss will be more than the distribution network without DG. (2) Node voltage. With the same location, if DG has larger capacity, which will increase the node voltage. The unreasonable capacity produces the overvoltage and threaten the system safety. (3) Power quality. Distributed generation is based on power electronic technology, a lot of power electronic converters increase a large amount of non-linear load, which will cause waveform distortion in current, voltage and harmonic pollution in power grid. (4) System protection. The protection device $s$ in distribution network cannot change a lot for DG, so DG must cooperate and adapt to existing protection scheme. DG may reduce the fault current through the feeder relay, which can disable relay protection. DG will change the fault level of distribution network. The variation trend of fault level depends on the number and variety of DG. The increasement of fault level requests to upgrade switch equipment, decreasement of fault makes trouble for overcurrent protection. (5)Unplanned island. If the distribution network suffers unexpected trip, part grid suddenly disconnects with the main grid. In the small grid, DG temporarily supply power to loads, this state is unplanned island. Due to unpredictability of unplanned island, it often cannot meet the requirements of power system safety and reliability.

The DG changes the network structure and flow direction of distribution network, which 
produces more problems in operation. Some technical issues, such as voltage regulation, protection configuration, overvoltage and power quality so on, need to be reconsidered. The upgrade of network structure and equipment is a fundamental way to solve the above problems, but it requires a lot of investment. The feasible method continue to use the existing network or makes little upgrade. Based on quantitative analysis for DG's influence on distribution network, the distribution network covers DG as many as possible, under the premise that guarantee the security and stability. Penetration level is the maximum capacity of DG can be acceptable to distribution network, under some constraints. According to the different requirements of the distribution system, the penetration level of DG has different mathematical models and analysis methods..

\section{Static Security Constraints Determine Penetration Level}

Based on radial distribution network, the influence on node voltage and power flow caused by location and capacity of DG is discussed [1]. The problem about maximum allowable penetration of DG can be simplified to active power maximization for DG under static security constraints. The paper models maximum allowable penetration of single DG and multiple DGs respectively and provides corresponding solution algorithm. The indexes of static security constraints primarily covers no overload and no overvoltage. In [2], the relationship between network loss and distribution generation capacity is analyzed, the continuation power flow method is used to calculate the flow of distribution network with DGs. The penetration level of DG can be determined under the constraints of voltage deviation and network loss.

In a simplified MV Italian distribution network, the impact of DG on voltage profiles [3], line current and short circuit currents was considered. The paper supposes that various generator positions dong the feeder and different values of supplied power in maximum and minimum load conditions.

Reference [4] uses maximum voltage deviation of customers, cables current limits, transformer nominal value as three main criteria to determine maximum photovoltaic penetration level in the grid. Further different locations are introduced to verify penetration level. Voltage profile and network loss limit the penetration of DG [5], the active network management (ANM) can be applied to increase the DG capacity, active power management of DG, on-load-tap-changer voltage control (OLTC) and reactive power compensating equipment are the three basic method in ANM [6]. Based on sensitivity of bus voltages and lines currents, the maximum capacity of DG locating in some line can be determined, search all buses to find the minimum acceptable penetration level [7]. If DG absorbs more reactive power from grid, DG units can compensate the voltage change they cause to increase the penetration level [8]. As same to [6], V-P and V-Q sensitivities can contribute to determine maximum allowable power, the voltage regulator devices can decrease the overvoltage caused by DG [9]. Energy losses and technical indexes taking into account several technical issues related to the interconnection of DG, limit the DG penetration level to 40-50\% [10].In consideration the work day, Saturday and Sunday, the difference between load curves makes the actual limit penetration the most restrictive [11] The various methods have different penetration level, the feeder voltages stay within ANSI Range A leads to the 30\% penetration level.

\section{Voltage Regulation Constraints Determine Penetration Level}

Compared to overvoltage in static security constraint, the voltage regulation focus on the on load tap changer transformer (OLTC) [12]. Combining with the outrage of DG, the OLTC can be described by switch function to build the voltage regeneration constraint. A bi-level optimal model is used to search the maximum penetration, the upper level model optimizes the penetration level of mult-DGs and the lower level optimization ensures that voltage constraints are satisfied even under the worst case [13]. The DG capacity affects the important parameter which is sensitivity of bus voltage with respect to tap changer, the illogical will cause OLTC oscillation, so the limits the allowable penetration of DG [14]. LDC (Line Drop Compensator) and OLTC constitute the voltage 
regulation method. On the basis of relationship between DG capacity and voltage regulation method, the penetration level of DG can be analyzed under proper voltage regulation of the power distribution system. The model can calculate the feasible operating range of DG at any interconnected point and at any time easily and quickly [15]. The tap changer of OLTC should in reasonable range to avoid over-voltage nor under-voltage, some paper define voltage range as Voltage Operational Margin (VOM) to estimate the critical PV penetration level [16]. Based on the discrete equation of the tap change under load (TCUL) transformers and the impact on the tap action caused by distributed generators [17], a optimization model is proposed considering tap hunting constraints. The reactive power compensation can improve penetration level.

\section{Harmonic Constraints Determine Penetration Level}

DG may inject harmonic current to connected distribution systems due to the power electronic converters. The larger capacity would cause total harmonic distortion (THD) beyond reasonable expectations. According to harmonic distortion constraints, the maximum penetrating level of multiple DGs can be computed based on a bi-level optimization model. When the large scale DGs access to distribution network, it is difficult to solve the bi-level optimization model [18]. V. Ravikumar Pandi evaluates the impact of DG penetration level and DG location by considering the power quality limits of IEEE Standard 519-1992 [19]. In the assessment of DG penetration level, the constraints consists of voltage limits, total harmonic distortion limits and individual harmonic distortion limits. The paper uses particle swarm optimization (PSO) algorithm, conventional power flow and decoupled harmonic power flow to estimate the maximum DG penetration levels on the IEEE 18-bus system [20]. Analytical methods are formulated to predict allowable distributed generation resources on a radial distribution feeder before voltage harmonic limits. The method also can achieve the given feeder load demand can be supplied by harmonic-injecting distributed resources with a 3\% individual voltage harmonic limits. Analytical method covers closed-form equations derived for typical feeder designs and different load allocation patterns. Minas Patsalides develops the high PV penetrations a detailed PV system model and regulates the model according to the data from true PV system [21]. The PV system model was inserted into industrial area and residential area to simulate its behavior. The voltage RMS (Root Mean Square) and the voltage THD (Total Harmonic Distortion) are analyzed to find the maximum penetration level. The capacity of PV can be almost 4 times the load demand, which does not cause noticeable voltage distortion. Based on power balance constraints, bus voltage limits, total and individual harmonic distortion limits specified by the IEEE-519 standard, over-current relay operating time limits, and protection coordination constraints. H. H. Zeineldin propose the operation size model for DG [22]. As a nonlinear programming (NLP) problem, the model is solved by PSO method to obtain the maximum DG penetration level. The result shows that higher penetration level is achieved when inverter-based and synchronous-based DG units are considered simultaneously compared to the only inverter type DG penetration case.

\section{Protection Constraints Determine Penetration Level}

With the distributed generation connected into the network, the power flow and short circuit current in the distribution network will be changed. Distribution protection system is designed by way of radial type of a signal source, DGs interconnection makes distribution network into a multisource network which cause the protection system not to work normally.

Tao Shun analyzes the impacts of penetration level and location of DG on key variables in the setting of traditional three-stage current protection [23]. Besides, the adaptability of the conditions by which the protection are set under the two conditions, the variation of allowed penetration level of DG under the fixed network-connected position and the change of network connected position under the fixed penetration level of DG, is emphatically analyzed, thus the allowed penetration level of DG for distribution feeder under a certain network-connected position and the scheme to choose the network-connected position under a certain penetration level of DG are quantitatively 
researched. (1)Make some improvement on the basis of the existing protection function [16], to make up the shortfall of over current protection, such as directional current protection [17], distance protection, pilot protection and differential protection. (2) Install disconnect switches and protection device along the feeder to avoid the whole feeder suffers outrage. (3) Coordinate line protection of distribution network with the protection of the distributed generation.

To solve the problem that the traditional distribution network fault section location scheme isn't applicable to the integration of DG, a method by limiting DG's access capacity to guarantee the traditional fault location methods available is proposed [24]. the requirements, that the minimum short-circuit current provided by the system power source and the maximum reverse short-circuit current provided by DG should satisfy for the traditional fault location methods to apply to distribution network with DGs, are proposed, which mean that the maximum access capacity of DGs are restricted. Results of calculation example show that on the basis of calculation of fault current reasonable switch value could be set up to distinguish the minimum current provided by the system power source and the maximum current provided by DG, which ensure that traditional fault section location scheme is available. Considering the effect of distributed generation connected into distribution networks on distribution protection system, Lei proposes the optimistic and pessimistic estimation of penetration level models [25]. Wang Jianghai proposes a method to determine maximum allowable capacity of DG for meeting the requirements of relay protection and limiting the impact to short-circuit current characteristics [26], and analyzes influence factors of the including the connection location, the composition of multiple DG and the line parameters in the distribution network. It is difficult to enlarge DG capacity with traditional protection scheme.

Because fuse fatigue occurrence is an unavoidable event with presence of DGs, reference [27] discusses an effective algorithm for minimum fuse change about eliminate this problem that will be presented at distribution feeders with distributed generation. Based on Digsilent software platform in which fault clearing time of each OCP device is available, we get four conditions by comparing "fault clearing time" for each fuse and recloser. (1) Fuse is operated faster than recloser. Though fuse-recloser coordination is lost, but fuse fatigue may not occur. (2) Fuse-recloser coordination had retained before presence of DG. But because increase of fault current due to presence of DG, fuse fatigue may be occurred. (3) Fuse is operated after recloser fast operation. Even after DG installation on feeder, fuse-recloser coordination completely retained, so this fuse can call a "good fuse" (4) Fuse-recloser coordination is lost before and after DG installation, fuse fatigue danger exist yet. The paper develops four the corresponding measures, the simulation results shows the method can determine maximum size of DG considering fuse fatigue issues. Load factor, load coincidence, and dispatchablilty of the DG influence the DG penetration levels without the transformer is overloaded or the fuse is damaged at peak load [28]. The maximum penetration of DG on a distribution component is equal to the distribution component rating plus the minimum component load at the time of peak generation. The effects of DG on distribution network current protection is analyzed. A calculation model of distribution network with DGs is built taking into account reliable action of relay protection device constraints, and a calculation method based on niche genetic algorithm is proposed [29].

\section{Conclusions}

This paper describes and analyzes different determine method for penetration level of DG. Static security constraints mainly considers node voltage and line capacity. Voltage regulation constraints focus on the on load tap changer transformer (OLTC). The harmonic constraints ensures the total harmonic distortion (THD) of node voltage within the limit. Protection constraints consider the influence of DG on fault current and existing protective equipment. The distribution system should take the four constraints into consideration to determine the maximum acceptable capacity of DG. 


\section{Acknowledgements}

This work was supported by Science and Technology Foundation of the State Grid Corporation of China for the project in 2014 " The key technology research and development for dynamic control and operation analysis of wide-area distributed generation”. Hao Bai is the corresponding author.

\section{References}

[1] Chengjun, X. Hong, C. Penetration capacity calculation for distributed generation considering static security constraints. Power System Technology, 33(16), 96-100, 2009.

[2] Xuefeng, F. Analysis of optimal placement of distributed generation capacity with limited power grid lose. Proceedings of the CSU-EPSA, 25(5): 121-126.

[3] Agustoni, A, \&Brenna, M. Constraints for the interconnection of distributed generation in radial distribution systems. 10th International Conference on Harmonics and Quality of Power, 2002.

[4] Kordkheili, R. A. Bak-Jensen, B. Determining maximum photovoltaic penetration in a distribution grid considering grid operation limits. PES General Meeting Conference \& Exposition, 2014.

[5] Abapour, A. Zare. K. Maximizing penetration level of distributed generations in active distribution networks. Smart Grid Conference (SGC), 2013.

[6] Karimi-Zare, P. Maximum allowable penetration level determination of a DG in a distribution network. Energy Conference and Exhibition (ENERGYCON), 2012.

[7] Morren, J. Maximum penetration level of distributed generation without violating voltage limits. SmartGrids for Distribution, 2008.

[8] Ayres, H. M. Freitas, W. Method for determining the maximum allowable penetration level of distributed generation without steady-state voltage violations. IET generation, transmission \& distribution, 4(4), 495-508, 2010.

[9] Celli, G. Ghiani, E. Multi-objective programming to maximize the penetration of distributed generation in distribution networks. Electricity Distribution-Part 1, 2009.

[10]Amaral Shayani, R. Penetration limit of photovoltaic distributed generation-Case study for the Italian Embassy in Brasília. International Conference on Clean Electrical Power, 2013.

[11]Hoke, A. Butler, R. Steady-state analysis of maximum photovoltaic penetration levels on typical distribution feeders. IEEE Transactions on Sustainable Energy , 4(2), 350-357,2013.

[12] Hu, H. Wu, S. Computing the maximum penetration level of multiple distributed generators in distribution network taking into account voltage regulation constraints. Proceedings of CSEE, 26(19), 13-17,2013.

[13]Wei, H. Jun, X. Penetration level calculation considering tap changer oscillations. Automation of Electric Power Systems, 31(14), 43-46, 2007.

[14]Kim, T. E. Kim, J. E. A method for determining the introduction limit of distributed generation system in distribution system. Power Engineering Society Summer Meeting, 2001.

[15]Kim, T. E. Kim, J. E. Considerations for the feasible operating range of distributed generation interconnected to power distribution system. Power Engineering Society Summer Meeting, 2002.

[16]Gonzalez, C. Weckx, S. Constrained PV penetration level in LV distribution networks based on the voltage operational margin. International Conference and Exhibition on Electricity Distribution, 2013.

[17]Wang, C. Hu, H.. Maximum penetration level computation of distributed generators in distribution network considering tap hunting constraints. Proceedings of the CSU-EPSA, 3, 005.

[18] $\mathrm{Hu}, \mathrm{H}$. Wu, S. Computing the maximum penetration level of multiple distributed generators in distribution network taking into account voltage regulation constraints. Proceedings of CSEE, 26(19): 13-17, 2006.

[19]Pandi, V. R. Allowable DG penetration level considering harmonic distortions. 37th Annual Conference on IEEE Industrial Electronics Society, 2011. 
[20]Bhowmik, A. Determination of allowable penetration levels of distributed generation resources based on harmonic limit considerations. Power Delivery, IEEE Transactions on, 18(2), 619624.

[21]Patsalides, M. Assessing the power quality behaviour of high photovoltaic (PV) penetration levels inside the distribution network. Power Electronics for Distributed Generation Systems (PEDG), 2012.

[22]Pandi, V. R. Determining optimal location and size of distributed generation resources considering harmonic and protection coordination limits. Power Systems, IEEE Transactions on, 28(2), 1245-1254, 2013.

[23] Shun, T. Jing, G. Analysis on allowed penetration level of distributed generation and its gridconnected position based on principles of current protection. Power System Technology, 36(1), 265-270, 2012.

[24]Tao, Z. Research on allowed penetration level of DGs based on the traditional fault location methods. Power System Technology, 38(8), 2257-2262, 2014.

[25]Jinyong, L. Wei, H. Penetration level calculation with considerations of phase-to-phase short circuit fault. Automation of Electric Power Systems, 32(3), 82-86, 2008.

[26]Wang, J. H, Tai, N. L. Penetration level permission of for DG in distributed network considering relay protection. Proceedings of the CSEE, 22, 37-43, 2010

[27]Sedaghati, A. An approach to determine penetration level of Distributed Generation considering fuse fatigue issues in distribution radial feeders. Advanced Power System Automation and Protection, 2011.

[28] Malmedal, K. Distributed energy resources and renewable energy in distribution systems: protection considerations and penetration levels. Industry Applications Society Annual Meeting, 2008.

[29]Chen, J. Fan, R. Penetration level optimization for DG considering reliable action of relay protection device constrains. International Conference on Sustainable Power Generation and Supply, 2009. 